\title{
Piezoelectric and structural properties of bismuth sodium potassium titanate lead-free ceramics for energy harvesting
}

Javier Eduardo Camargo ( $\square$ jcamargo@fi.mdp.edu.ar )

INTEMA https://orcid.org/0000-0003-2358-7935

\section{Santiago Osinaga}

Universidad Tecnológica Nacional FRBB

Mariano Febbo

Universidad Nacional del Sur

Sebastián P. Machado

Universidad Tecnológica Nacional FRBB

\section{Fernando Rubio-Marcos}

Instituto de Cerámica y Vidrio: Instituto de Ceramica y Vidrio

Leandro Ramajo

INTEMA

Miriam Castro

INTEMA

\section{Research Article}

Keywords: Lead-Free, BNKT, energy harvesting

Posted Date: June 3rd, 2021

DOl: https://doi.org/10.21203/rs.3.rs-185744/v1

License: (c) (i) This work is licensed under a Creative Commons Attribution 4.0 International License. Read Full License 


\section{Piezoelectric and structural properties of bismuth sodium}

\section{potassium titanate lead-free ceramics for energy harvesting}

Javier Camargo $^{\mathrm{a}^{*}}$, Santiago Osinaga ${ }^{\mathrm{b}}$, Mariano Febbo ${ }^{\mathrm{c}}$, Sebastián P. Machado ${ }^{\mathrm{b}}$, Fernando Rubio-Marcos ${ }^{\mathrm{d}, \mathrm{e}}$, Leandro Ramajo ${ }^{\mathrm{a}}$, Miriam Castro ${ }^{\mathrm{a}}$

${ }^{\text {a }}$ Institute of Research in Materials Science and Technology (INTEMA), Juan B. Justo 4302, Mar del Plata B7608FDQ, Argentina.

${ }^{\mathrm{b}}$ Grupo de Investigación de Multifísica Aplicada, Universidad Tecnológica Nacional FRBB, 11 de abril 461, 8000 Bahía Blanca, Buenos Aires, Argentina., smachado@frbb.utn.edu.ar

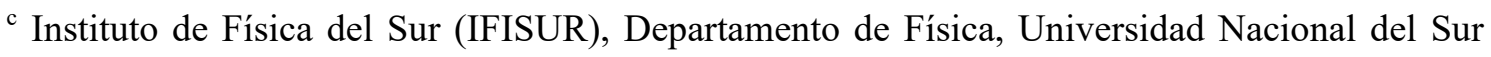
(UNS), Avda. Alem 1253, B8000CPB, Bahía Blanca, Argentina, mfebbo@uns.edu.ar

d Electroceramic Department, Instituto de Cerámica y Vidrio, CSIC, Kelsen 5, 28049 Madrid, Spain.

${ }^{e}$ Escuela Politécnica Superior. Universidad Antonio de Nebrija, Pirineos 55, 28040, Madrid, Spain

*Author to whom correspondence should be addressed Email: jcamargo@fi.mdp.edu.ar 


\begin{abstract}
:
The development of bulk piezoelectric ceramics with high energy conversion efficiency is of decisive importance for the requirements of the advanced energy harvesting devices toward miniaturization and integration. There is an additional motivation in the piezoelectric ceramics, lead titanate-zirconate (PZT) ceramics are the most widely used energy harvesting $(\mathrm{EH})$ materials. This fact is important because legal restrictions on the use of lead in electronic devices have led to greater efforts being made to develop leadfree alternatives to PZT-based materials. Here, we propose the $\mathrm{Bi} 0.5\left(\mathrm{Na}_{0.8} \mathrm{~K}_{0.2}\right)_{0.5} \mathrm{TiO}_{3}$ (BNKT) lead-free piezoceramics as a good candidate for the replacement of toxic lead compounds for energy harvesting applications. For that, we have carried out a systematic study of the voltage generation of BNKT-based piezoceramics for $(\mathrm{EH})$ purposes. Specifically, our results reveal that the BNKT-based lead-free piezoceramics show adequated effective capacitance and output energy due to more effective performance with a piezoelectric charge coefficient and a maximum generated output voltage as high as $12.8 \mathrm{pC} / \mathrm{N}$ and $19.9 \mathrm{~V}$, respectively. Finally, we consider that the design of new leadfree piezoceramics with superior property coefficients and functionalities, such as the BNKT-based piezoceramics, should be seriously considered as candidates for the replacement of the current toxic lead-based compounds.
\end{abstract}

Keywords: Lead-Free, BNKT, energy harvesting 


\section{INTRODUCTION}

Energy harvesting is one of the most promising techniques for a wide variety of selfpowered systems. Among the sources for energy harvesting, we can find solar power, thermal gradients, and vibration [1,2]. In recent years, the attention of many researchers has been focused on mechanical vibration as a potential source of energy, since it is easily accessible through microelectromechanical systems (MEMS), and it is ubiquitous in applications ranging from small household appliances to large infrastructures [3-6]. Furthermore, piezoelectric materials have a high energy conversion efficiency and good power generation, in addition to the relatively low weight and volume characteristics that are becoming more important with the development of the renewable energy industries [7].

Different kinds of piezoelectric energy harvesters (PEHs) to extract energy from mechanical vibrations are reported [8]. Their fundamental advantages are based on the high electromechanical coupling that means a large strain/voltage conversion, the possible miniaturization, and the absence of the requirement of an external voltage $[9,10]$. Generally, this application uses piezoelectric ceramics based on lead zirconate titanate materials, known as PZT. However, legal restrictions on the use of lead in electric and electronic devices have been increased the efforts related to the development of lead-free alternatives to PZT-based piezoelectric ceramics. Recent reports have identified many possible lead-free candidates based on potassium sodium niobates $(\mathrm{K}, \mathrm{Na}) \mathrm{NbO}_{3}(\mathrm{KNN})$ $[11,12]$; sodium bismuth titanates $(\mathrm{Bi}, \mathrm{Na}) \mathrm{TiO}_{3}(\mathrm{BNT})$ or potassium bismuth titanates $(\mathrm{Bi}, \mathrm{K}) \mathrm{TiO}_{3}(\mathrm{BKT})$ [13]. The $\mathrm{KNN}$ phase, discovered in the late 1950s, exhibits a piezoelectric coefficient $\left(\mathrm{d}_{33}\right)$ close to $80 \mathrm{pC} / \mathrm{N}$, and a Curie temperature of $420^{\circ} \mathrm{C}$ for the Polymorphic phase boundary (PPB) composition [14]. However, the difficulty to reach 
pure and dense KNN-based piezoelectric ceramics stimulates the use of new compositions.

Sodium bismuth titanate $\mathrm{Bi}_{0.5} \mathrm{Na}_{0.5} \mathrm{TiO}_{3}$ (BNT) with a large remnant polarization at room temperature and a relatively high Curie temperature could be considered as a possible candidate to replace PZT-based piezoelectric ceramics [15]. Due to the high coercive field of BNT-based piezoceramics, numerous studies have been carried out to improve the electrical properties of BNT by the formation of solid solutions with other $\mathrm{ABO}_{3}$ perovskites $[16,17]$. In the $\mathrm{Bi}_{0.5} \mathrm{Na}_{0.5} \mathrm{TiO}_{3}-\mathrm{Bi}_{0.5} \mathrm{~K}_{0.5} \mathrm{TiO}_{3}(\mathrm{BNKT})$ solid solution, $\mathrm{Na}^{+}$is partially substituted by $\mathrm{K}^{+}$on the A-site of BNT, and it is known that high strain and ferroelectric properties can be achieved [18].

The present work aims to analyze the power generation of the BNKT ceramics coupled to a base excited cantilever steel beam . The obtained results are contrasted with other ceramics reported by other authors. Besides, the structure and microstructure of the BNKT ceramics are studied to relate them to the ferroelectric and piezoelectric properties.

\section{MATHEMATICAL DESCRIPTION AND MODELLING}

The system under study comprises a plate-shaped lead-free piezoelectric material based on $\mathrm{Bi}_{0.5}\left(\mathrm{Na}_{0.8} \mathrm{~K}_{0.2}\right)_{0.5} \mathrm{TiO}_{3}(\mathrm{BNKT})$, attached to a steel beam that supports it (see Fig. 1). All the system is excited by its base over the shape of a deterministic function $g(t)$, which tries to mimic an environmental excitation from which energy can be extracted. 


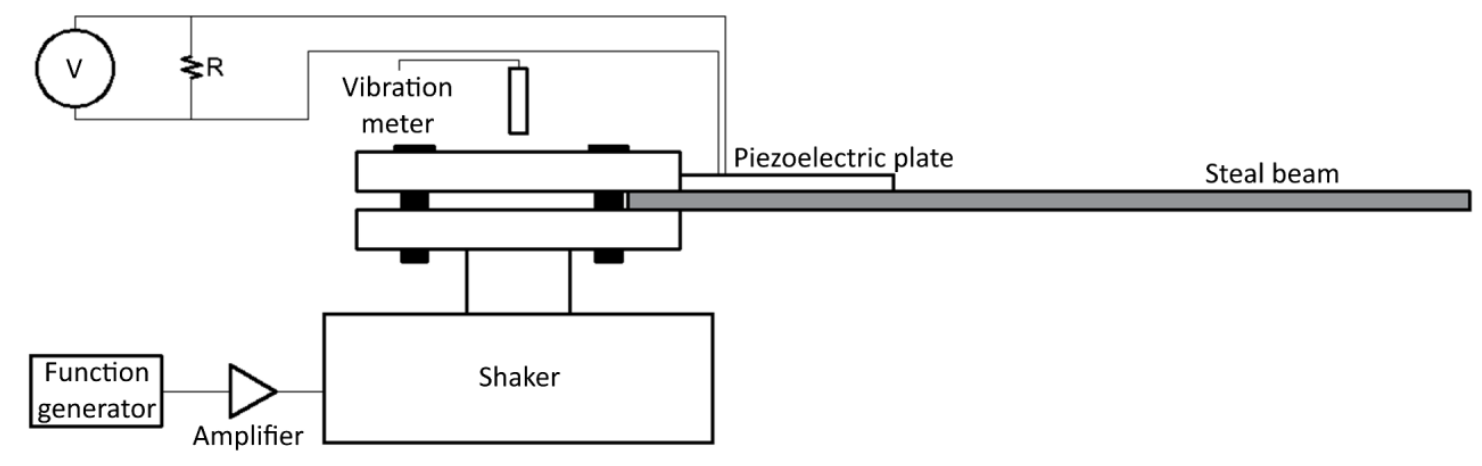

Figure 1. Schematic diagram of the experimental setup.

A linear formulation previously developed by the authors, according to BernoulliEuler beam theory, is used. For the sake of brevity, we refer to previous works $[19,20]$ to see the complete derivation of the electromechanical equations. The solution gives the voltage generation (1), the beam displacement (2), and the amplitude of the modal coordinate (3), assuming a harmonic excitation:

$$
\begin{gathered}
V=\sum_{j=1}^{N} \frac{\theta_{j} \Omega R}{\sqrt{1+C^{2} R^{2} \Omega^{2}}} \bar{\eta}_{j} \\
w(x, t)=\sum_{j=1}^{N} \Phi_{j}(x) e^{i \Omega t} \bar{\eta}_{j} \\
\bar{\eta}_{j}=\frac{\Gamma_{j} \sqrt{1+C^{2} R^{2} \Omega^{2}}}{\sqrt{\left(\omega_{j}^{2}-\Omega^{2}-2 C R \xi_{j} \omega_{j} \Omega^{2}\right)^{2}+\left(2 \Omega \xi_{j} \omega_{j}+R \Omega\left(\theta_{j}^{2}+C \omega_{j}^{2}-C \Omega^{2}\right)\right)^{2}}}
\end{gathered}
$$

where the subscript notation was used to denoted parameters associated with the $j$-th natural frequency and mode shape of the vibrating system, being: $\Phi_{j}$ the mode shape function, $\Gamma_{j}$ the modal coupling, $\theta_{j}$ the piezoelectric coupling, $\Omega$ the excitation frequency, $R$ the resistive load, $\omega_{j}$ the natural frequency, $C$ the capacity of the piezoelectric disc and 
$\xi_{j}$ the modal damping coefficient. The expression for the piezoelectric coupling can be expressed as:

$$
\theta_{j}=b_{p} e_{31}\left(a+\frac{h_{p}}{2}\right) \Phi_{j}\left(L_{1}\right)
$$

where $b_{p}$ and $h_{p}$ are the width and thick of the piezo, $\mathrm{e}_{31}$ is a piezoelectric constant and a is the distance between the neutral axis and the contact axis of the materials.

\section{EXPERIMENTAL DETAIL OF THE HARVEST FABRICATION}

Sample Preparation. $\mathrm{Bi}{ }_{0.5}\left(\mathrm{Na}_{0.8} \mathrm{~K}_{0.2}\right)_{0.5} \mathrm{TiO}_{3}(\mathrm{BNKT})$ powder was synthesized through the solid-state reaction method, using $\mathrm{K}_{2} \mathrm{CO}_{3}$ and $\mathrm{Na}_{2} \mathrm{CO}_{3}$ (Aldrich 99.5\%; USA), $\mathrm{Bi}_{2} \mathrm{O}_{3}$ (Aldrich 99.8\%; USA) and $\mathrm{TiO}_{2}$ (Aldrich 99.9\%; USA). Powders were mixed and milled using zirconia balls in an alcoholic medium for $3 \mathrm{~h}$ in a planetary mill (Fritsch, Pulverisette 7, $1010 \mathrm{rpm})$. Powders were dried and calcined at $700{ }^{\circ} \mathrm{C}$ for $2 \mathrm{~h}$. The resulting powders were milled for $1.5 \mathrm{~h}$ again and pressed into discs of $20 \mathrm{~mm}$ diameter, which were sintered at $1100{ }^{\circ} \mathrm{C}$ for 5 hours.

Finally, the sintered disc of $20 \mathrm{~mm}$ diameter and $1.2 \mathrm{~mm}$ thickness was cut into a 9.2 $\mathrm{mm} \times 12.15 \mathrm{~mm}$ plate. After that, the plate was attached to a steel beam of a total length of $110 \mathrm{~mm}$, which acts as its support. All the system was harmonically excited by an electromechanical shaker (Labworks ET-132) powered by the amplified signal from a function generator (RIGOL DG46062). Base velocity was measured by a laser vibrometer (Polytec PDV-100) whose signal was numerically differentiated to obtain its acceleration. This signal, along with the generated voltage, is collected by the acquisition board (NI 9234) at 2048 samples/sec, and then, post-processed by an own implemented code.

Structural and Microstructural Characterization. Crystalline phases were characterized by X-ray diffraction, XRD (PANalytical, X'pert Pro, CuKa). Density values were determined using Archimedes' method. Ceramic samples were polished and 
grain boundaries were highlighted through a chemically etching step employing a solution of $\mathrm{HCl}$ and $\mathrm{HF}$. Etched samples were analyzed by Scanning Electron Microscope, SEM (Jeol JSM-6460LV). Raman microspectrometric analyses of samples were carried out on a multichannel Renishaw In Via Reflex microspectrometer using a $514 \mathrm{~nm}$ line of an Ar laser. To achieve an enhanced signal-to-noise ratio, 30-50 scans were collected, employing a $15 \mathrm{~s}$ exposure time and a laser power ranging between 30 and $300 \mathrm{~mW}$.

The elastic module was obtained through nanoidentification techniques with a nanoindenter (Hysitron TI 980 Nanoindenter, Bruker) according to the standard ISO 14577.

Electrical characterization. Previous to the electrical measurements, a fired silver paste was used for the electric contacts. The temperature dependence of the dielectric properties was determined using an impedance analyzer (Hewlett-Packard, HP4284A) over a frequency range of $100 \mathrm{~Hz}-1 \mathrm{MHz}$. Samples were polled in a silicone oil bath at $100^{\circ} \mathrm{C}$ by applying a DC field of $30.0 \mathrm{kV} / \mathrm{cm}$ for $10 \mathrm{~min}$. The piezoelectric constant $\mathrm{d}_{33}$ was measured using a piezo d33 meter (YE2730A d33 METER, APC International, Ltd., USA). The polarization-electric field (P-E) hysteresis loops were measured in a silicon oil bath using a modified Sawyer-Tower circuit. The electromechanical planar coupling factor $\left(\mathrm{K}_{\mathrm{p}}\right)$ was calculated from the impedance curves of the polarized ceramics, according to equation 5 .

$$
K_{p}=\sqrt{2.51\left\{\frac{f_{a}-f_{r}}{f_{a}}\right\}}
$$

where $f_{a}$ is the anti-resonance frequency and $f_{r}$ is the resonance frequency. 


\section{RESULTS AND DISCUSSION}

1. Morphological and structural characterization of the $\mathrm{Bi}_{0.5}\left(\mathrm{Na}_{0.8} \mathrm{~K}_{0.2}\right)_{0.5} \mathrm{TiO}_{3}$ (BNKT) lead-free piezoceramics.

In piezoceramics materials, the microstructural features play a relevant role in the functional properties and, therefore, their grain morphology and distribution can be used to plan new strategies in designing new materials with improved functional properties. From Figure 2a, it can be observed that the ceramic sample has a dense and refinement microstructure with the typical feature of rounded cubic grains which is common in BNKT-based ceramics. The density value obtained for this sample is $5.76 \mathrm{~g} / \mathrm{cm}^{3}(96.6 \%$ of the theoretical value) and the average grain size is close to $\sim 0.50 \pm 0.2 \mu \mathrm{m}$ as it is shown in the inset of Figure 2a. In brief, the final microstructure of the BNKT lead-free system is characterized by a uniform and sub-micrometer grain size, which is suitable as it leads to a high density of this ceramic. Consequently, both qualities (uniform microstructure and high density) are suitable for the development of improved energy harvesting properties.

As it is widely known, the surprising properties revealed by the bismuth potassium sodium titanate $(\mathrm{BNKT})$ based materials have their origin in the presence of a morphotropic phase boundary (MPB) [21]. To evaluate MPB on BNKT-based piezoceramics is frequently used the X-ray diffraction [22]. Figure $\mathbf{2 b}$ presents the X-ray diffraction patterns of the BNKT ceramic. The diffraction pattern can be assigned to a perovskite-phase without traces of secondary phases at room temperature, within the XRD resolution [23]. The first insert of Fig. $\mathbf{2 b}$ shows the peak near $40^{\circ}$ that there is split into two peaks corresponding to the (111) pseudo-cubic peak, suggesting a non-cubic symmetry in this sample. The coexistence of different polymorphs was previously reported on BNKT bulk ceramics [24,25]. The splitting of the (111) reflection in the 
$38.5^{\circ}-41.5^{\circ}$ range can be attributed to the coexistence between a rhombohedral symmetry and a tetragonal symmetry. To reinforce this observation, it can be seen that the $(002)$ pseudo-cubic also undergoes a splitting. Again, this fact demonstrates that the BNKT ceramics present the coexistence of different polymorphs formed between rhombohedral and tetragonal phases.

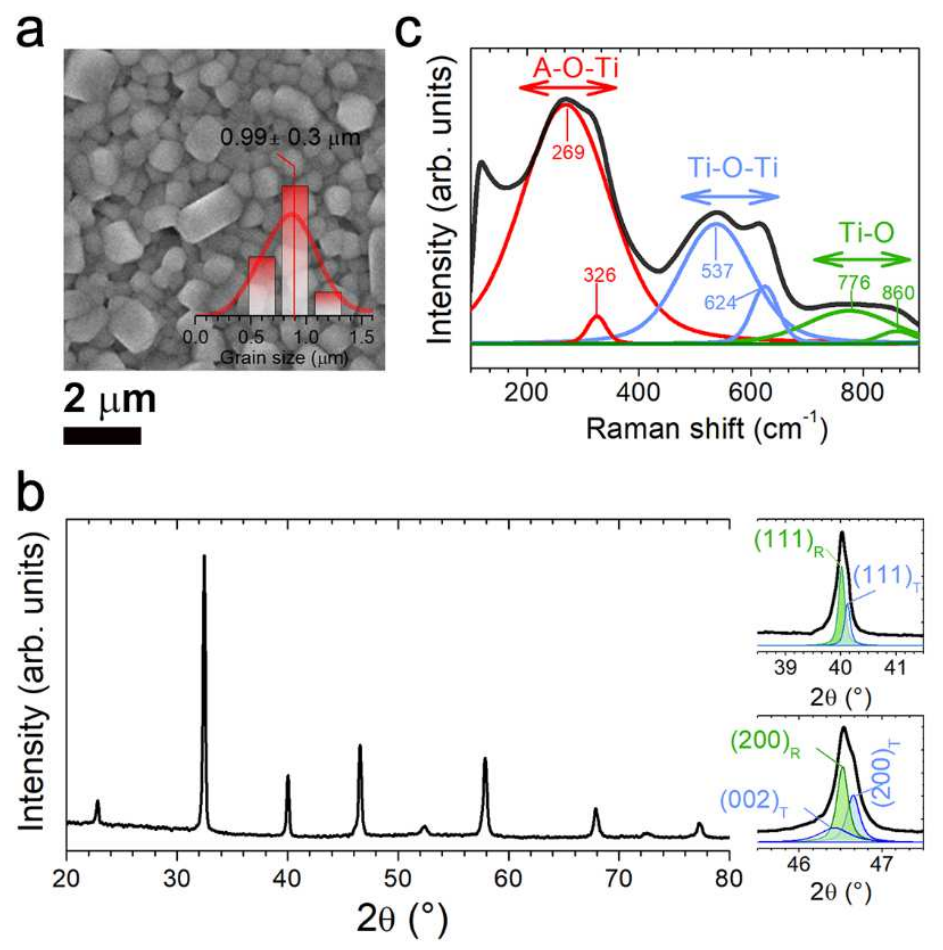

Figure 2. Microstructural and structural features of the $\mathrm{Bi}_{0.5}\left(\mathrm{Na}_{0.8} \mathrm{~K}_{0.2}\right)_{0.5} \mathrm{TiO}_{3}$ ceramics: a. Microstructure of polished and thermally etched surfaces of the BNKT ceramics. Additionally, the insert of the panel a shows the grain size distribution as well as the average grain size of BNKT ceramics. b. XRD pattern corresponding to the BNKT ceramic sintered at $1100^{\circ} \mathrm{C}$ for $5 \mathrm{~h}$. The inserts of Fig. 2b shows the magnified XRD diffraction pattern in the $2 \Theta$ range $38.5^{\circ}$ to $41.5^{\circ}$ and $45.5^{\circ}$ to $47.5^{\circ}$ of the BNKT ceramic. The splitting of the (111) pseudo-cubic is fitted to the sum of two Lorentzian peaks, which are indexed as 1 tetragonal peak (in blue color) plus 1 rhombohedral peak (in green color) of the perovskite phase. Whilst the splitting of the (002) pseudo-cubic is simulated to the sum of the three Lorentzian peaks, which are indexed as 2 tetragonal peaks (in blue color) plus rhombohedral peak (in green color) of the perovskite phase. Finally, the panel c shows the Raman spectrum of the sintered sample where the corresponding deconvoluted modes.

Figure 2c shows the Raman spectra of BNKT sintered samples. Raman results are in agreement with previously reported data. Peaks around 269 and $326 \mathrm{~cm}^{-1}$ could be 
attributed to the A-O-Ti stretching containing short $\mathrm{Ti}-\mathrm{O}$ bonds (where A corresponding to A-site of the perovskite phase), whereas bands at 537 and $624 \mathrm{~cm}^{-1}$, approximately, can be assigned to the $\mathrm{Ti}-\mathrm{O}-\mathrm{Ti}$ stretch in edge-shared $\mathrm{TiO}_{6}$. Bands close to 776 and 860 $\mathrm{cm}^{-1}$ are related to a short $\mathrm{Ti}-\mathrm{O}$ stretching vibration in distorted $\mathrm{TiO}_{6}$. Broadbands due to the A-site disorder structure and to different Raman-modes overlapped are observed [26]. Moreover, the band located at $326 \mathrm{~cm}^{-1}$ which is assigned to the tetragonal phase formation, confirms the stabilization of the morphotropic phase detected by XRD studies. In short, BNKT ceramic sample presents a morphotropic behavior, which is associated with the room temperature coexistence between a rhombohedral symmetry and a tetragonal symmetry. Again, this fact favors the polarization rotation phenomenon because the energy profile flattens in this region [22], which has been reported as one of the origins of the properties enhancement at MPB regions.

\section{Determination of the phase transition temperatures and the functional} properties of the $\mathrm{Bi}_{0.5}\left(\mathrm{Na}_{0.8} \mathrm{~K}_{0.2}\right)_{0.5} \mathrm{TiO}_{3}(\mathrm{BNKT})$ lead-free piezoceramics.

The actual working conditions of piezoceramic materials often depend on thermal conditions. Therefore, additional experiments were performed from their dielectric permittivity $\left(\varepsilon^{\prime}\right) v s$. T curves as well as hysteresis loops of BNKT ceramics sintered at $1100^{\circ} \mathrm{C}$ for $5 \mathrm{~h}$ (see Figure 3). BNKT samples exhibit high real permittivity and low dielectric loss values in the analyzed temperature range (see Figure 3a-b) where the depolarization temperature $\left(T_{d}\right)$ is not observed. On the other hand, hysteresis loops at different temperatures (Figure 3c) of BNKT samples exhibit remnant polarization values (Pr) between $4.8 \mu \mathrm{C} / \mathrm{cm}^{2}$ at $30^{\circ} \mathrm{C}$ and $3.0 \mu \mathrm{C} / \mathrm{cm}^{2}$ at $120^{\circ} \mathrm{C}$; while the coercive field (Ec) varies between $12.5 \mathrm{kV} / \mathrm{cm}$ at $30^{\circ} \mathrm{C}$ and $4.5 \mathrm{kV} / \mathrm{cm}$ at $120^{\circ} \mathrm{C}$. These values are in agreement with those observed by other authors [24,27]. 


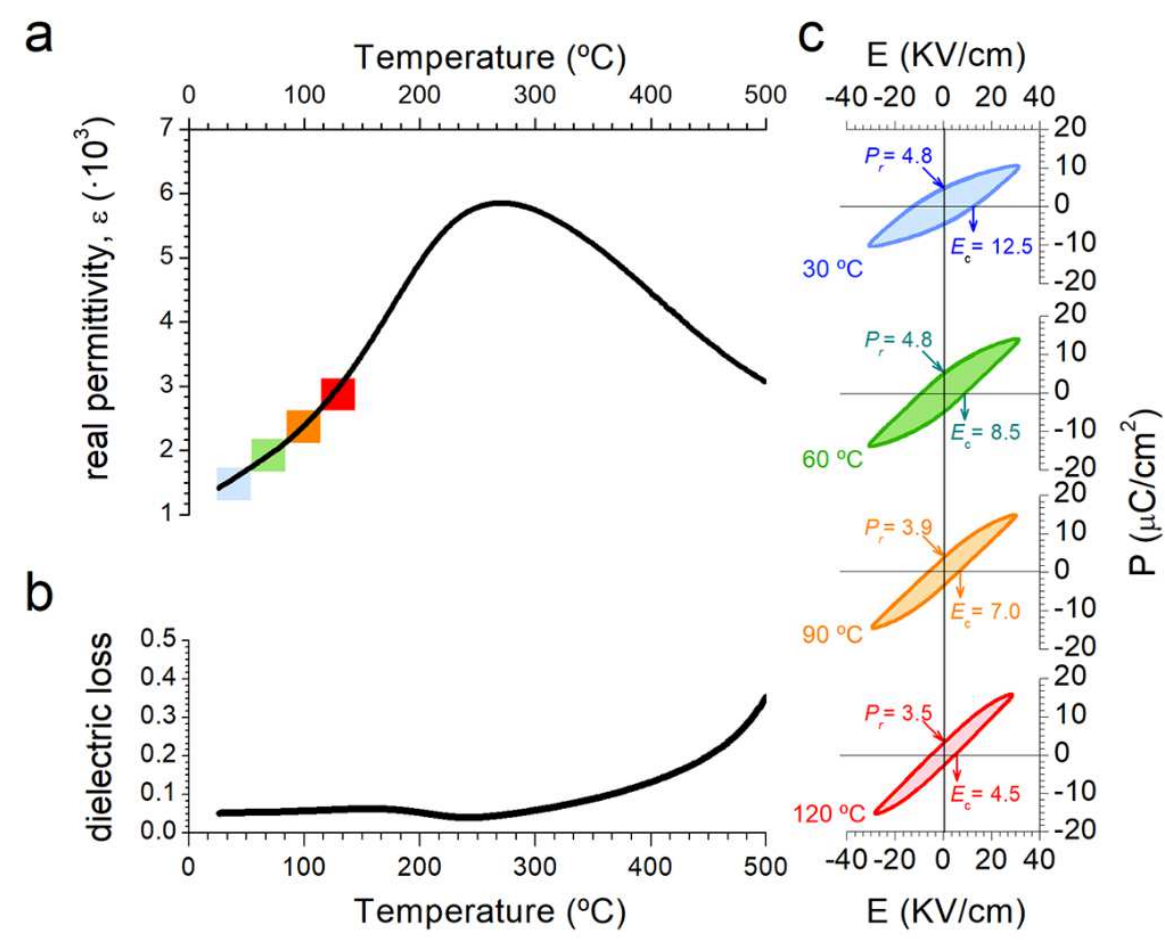

Figure 3. Electrical feactures as a function of the temperature of the $\mathrm{Bi}_{0.5}\left(\mathrm{Na}_{0.8} \mathrm{~K}_{0.2}\right)_{0.5} \mathrm{TiO}_{3}$ ceramics: a. Real permittivity $\left(\varepsilon^{\prime}\right)$ and $\mathbf{b}$. dielectric loss $v s$. temperature of BNKT sintered ceramics (at $10 \mathrm{kHz}$ ). c. A set of the hysteresis loops at different temperatures $\left(30^{\circ} \mathrm{C}\right.$ to $\left.120^{\circ} \mathrm{C}\right)$. The regions delimited by color áreas marked in panel $\mathbf{a}$, indicate the four different temperatures of the panel $\mathbf{c}$.

The measured piezoelectric constant $\left(\mathrm{d}_{33}\right)$, elastic modulus $\left(\mathrm{E}_{33}\right)$, density $(\delta)$, real permittivity $\left(\varepsilon^{\prime} 33\right)$, dielectric loss $(\tan \delta)$, coupling factor $\left(\mathrm{K}_{\mathrm{p}}\right)$, and piezoelectric voltage coefficient $\left(\mathrm{g}_{33}=\mathrm{d}_{33} / \varepsilon_{0} \varepsilon^{\prime}{ }_{33}\right)$ of the plate sample are shown in Table 1. According to the structural and microstructural characterization and the electrical and mechanical properties shown in Table 1, it is possible to confirm that the BNKT samples obtained by the solid-state reaction method and sintered at $1100^{\circ} \mathrm{C}$ for $5 \mathrm{~h}$ have good ferroelectric properties in comparison with those reported by other authors $[28,29]$. 
Table 1. Elastic modulus $\left(\mathrm{E}_{33}\right)$, density $(\delta)$, real permittivity $\left(\varepsilon_{33}^{\prime}\right)$, dielectric loss $(\tan \delta)$, electromechanical planar coupling factor $\left(\mathrm{K}_{\mathrm{p}}\right)$, piezoelectric constant $\left(\mathrm{d}_{33}\right)$, and piezoelectric voltage coefficient $\left(\mathrm{g}_{33}\right)$ values of sintered samples and measured at $30^{\circ} \mathrm{C}$ and $10 \mathrm{kHz}$.

\begin{tabular}{|c|c|c|c|c|c|c|}
\hline $\begin{array}{c}\mathrm{E}_{33} \\
(\mathrm{GPa})\end{array}$ & $\begin{array}{c}\delta \\
\left(\mathrm{g} / \mathrm{cm}^{3}\right)\end{array}$ & $\varepsilon^{\prime} 33$ & $\tan \delta$ & $\mathrm{Kp}$ & $\begin{array}{c}\mathrm{d}_{33} \\
(\mathrm{pC} / \mathrm{N})\end{array}$ & $\begin{array}{c}\mathrm{g}_{33} \\
\left(10^{-3} \mathrm{Vm} / \mathrm{N}\right)\end{array}$ \\
\hline 92 & 5.76 & 1050 & 0.061 & 0.19 & 129 & 13.9 \\
\hline
\end{tabular}

\section{Finding a potential technological application of the $\mathrm{Bi} 0_{0.5}\left(\mathrm{Na}_{0.8} \mathrm{~K}_{0.2}\right)_{0.5} \mathrm{TiO}_{3}$ ceramics for energy harvesting.}

In what follows, the piezoelectric energy harvesting performance is shown. The experimental setup of the ceramic sample attached to a steel beam mounted in an electrodynamical shaker is shown in Figure 4a. Figure $\mathbf{4 b}$ presents the voltage to base acceleration FRF (Frequency response function) near the first natural frequency of the system (Fig. 4b). The experiment was performed using a fixed resistance of $248 \mathrm{k} \Omega$. This value results from the equivalent resistance of the commercial resistive load connected in parallel with the data acquisition system's input resistance. Note that the voltage value is divided by the base acceleration to obtain a voltage to base acceleration FRF (in units of $\left.g=9.81 \mathrm{~m} . \mathrm{s}^{-2}\right)$. In the case of voltage generation, the maximum value $\left(V \cdot g^{-1}\right)$ was $\sim 19.9$ for the plate specimens of BNKT. The power density generated by the BNKT was 0.28 $\mathrm{mW} / \mathrm{cm}^{3}$ giving good values compared to other lead-free piezoelectric ceramics. Recalling the predicted voltage expressed in Eq. 1, it can be observed that there are two unknown parameters: the $\mathrm{d}_{31}$ arising from the electromechanical coupling $\theta_{j}$ (defined by Eq. 4) and the damping coefficient $\xi_{\mathrm{j}}$ arising from the modal coordinate (defined by Eq. 3). These values were identified from the experimental results by the curve fitting according to the least square method. The numerical results, along with the peak value, are shown in Table 2. 
a

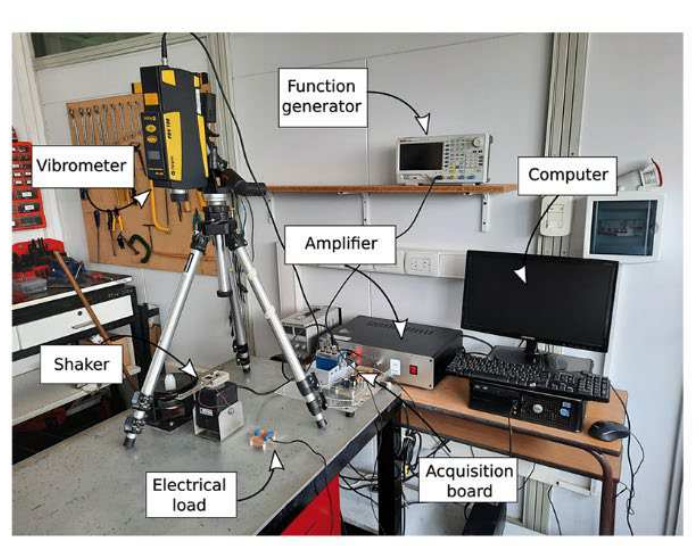

C

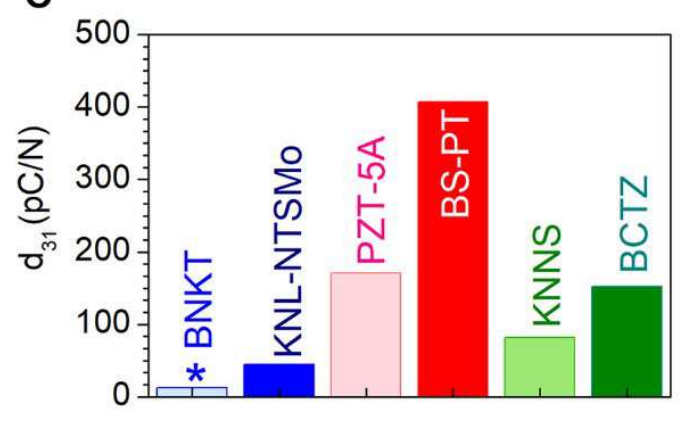

b

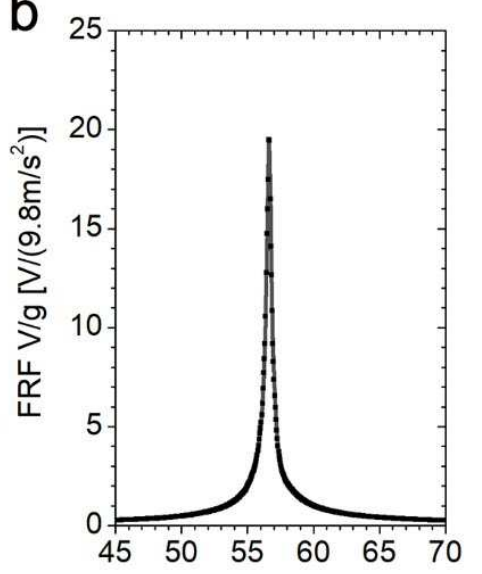

d

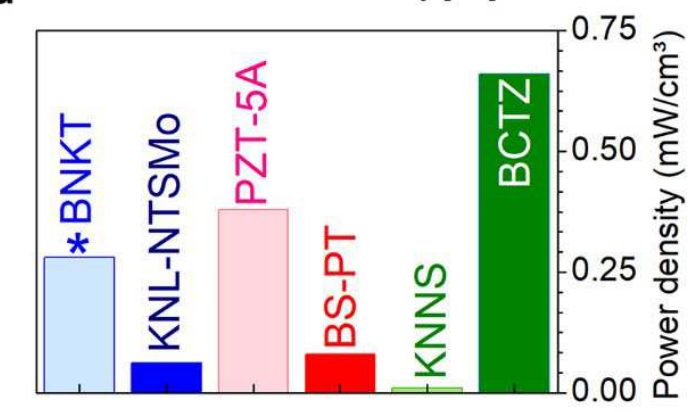

Figure 4. Finding a potential technological application of the $\mathrm{Bi}_{0.5}\left(\mathrm{Na}_{0.8} \mathrm{~K}_{0.2}\right)_{0.5} \mathrm{TiO}_{3}$ ceramics for energy harvesting. a, Experimental setup of the tested sample.b, Voltage to base acceleration FRFs for frequencies near the first mode of the electromechanical system for a given resistor. c-d, A comparison of Piezoelectric constant $\left(\mathrm{d}_{31}\right)$ and power density among lead-free and lead-based ceramics [7,30-33]. The asterisk marked in panels $\mathbf{c}$ and $\mathbf{d}$ corresponds to the values determined in this study for the BNKT system.

Table 2. Piezoelectric constant $\left(\mathrm{d}_{31}\right)$, damping coefficient $\left(\xi_{1}\right)$, and generated voltage $(\mathrm{V} / \mathrm{g})$ of the samples with a plate shape.

\begin{tabular}{|c|c|c|c|}
\hline Sample & $\mathrm{d}_{31}(\mathrm{pC} / \mathrm{N})$ & $\xi_{1}$ & $V / g$ (peak) \\
\hline Plate & -12.8 & 0.0031 & 19.9 \\
\hline
\end{tabular}

A comparison of the piezoelectric constant $\left(\mathrm{d}_{31}\right)$ and power density values lead-free and lead-based bulk ceramics is shown in Figure 4c-d. By comparing the present material (BNKT) with other lead-free piezoelectric ceramics (such as KNNS and KNL-NTS), a 
higher power density value is observed for the BNKT despite it exhibits a low $\mathrm{d}_{31}$ value (see Figure 4d and 4c, respectively).

Moreover, the power density obtained in this work, for a lead-free composition, is similar to that registered by the commercial lead-based PZT-5A[34]. Finally, even though BCZT ceramics presented higher power density values, the high sintering temperature (between 1350 and $\left.1450{ }^{\circ} \mathrm{C}\right)[33]$ and the low operating temperature $\left(<100^{\circ} \mathrm{C}\right)$ required for these compositions, encourage the use of BNKT-based lead-free compositions for energy harvesting devices.

\section{Conclusions}

This study presents an advance in the lead-free piezoelectric ceramics field, expanding their applications for energy harvesting devices. Specifically, the microstructural and structural features of the $\mathrm{Bi}{ }_{0.5}\left(\mathrm{Na}_{0.8} \mathrm{~K}_{0.2}\right)_{0.5} \mathrm{TiO}_{3}$ ceramics reveal that the system presents a morphotropic behavior, which favors the polarization rotation phenomenon because the energy profile flattens in this region. This fact is reflected in its good ferro-piezoelectric properties in comparison with those reported by other authors $[28,29]$. It is worth pointing out that these features observed here could have potential technological applications for energy harvesting. To reinforce our idea, we found that the BNKT-based lead-free piezoceramics developed a piezoelectric charge coefficient and a maximum generated output voltage as high as $12.8 \mathrm{pC} / \mathrm{N}$ and $19.9 \mathrm{~V}$ for $1 \mathrm{~g}$ base acceleration, respectively. Most relevant, we have determined that the BNKT-based system generates a power density of $0.28 \mathrm{~mW} / \mathrm{cm}^{3}$, confirming that the BNKT-based system could be a suitable candidate to be used in piezoelectric energy harvesting applications.

\section{CONFLICTS OF INTEREST}

There are no conflicts to declare. 


\section{ACKNOWLEDGMENT}

The authors gratefully acknowledge the support of the ANPCyT (Argentina, PICT 2014-1314), CONICET (Argentina), UNMdP (Argentina), AEI (Spanish Government, MAT2017-86450-C41-R) projects. F.R-M is indebted to MINECO for a 'Ramon y Cajal' contract (ref: RyC-201518626), which is co-financed by the European Social Fund. F.R-M also acknowledges support from a 2018 Leonardo Grant for Researchers and Cultural Creators (BBVA Foundation). 


\section{References}

1. S. Chiba, M. Waki, T. Wada, Y. Hirakawa, K. Masuda, and T. Ikoma, Appl. Energy 104, 497 (2013).

2. D. M. Sun, K. Wang, X. J. Zhang, Y. N. Guo, Y. Xu, and L. M. Qiu, Appl. Energy 106, 377 (2013).

3. A. Delnavaz and J. Voix, Smart Mater. Struct. 23, 105020 (2014).

4. Y. C. Shu and I. C. Lien, J. Micromechanics Microengineering 16, 2429 (2006).

5. W. S. Kang and J. H. Koh, J. Eur. Ceram. Soc. 35, 2057 (2015).

6. G. Lee, D. J. Shin, Y. H. Kwon, S. J. Jeong, and J. H. Koh, Ceram. Int. 42, 14355 (2016).

7. S. P. Machado, M. Febbo, F. Rubio-Marcos, L. A. Ramajo, and M. S. Castro, Smart Mater. Struct. 24, 115011 (2015).

8. I.-T. Seo, C.-H. Choi, D. Song, M.-S. Jang, B.-Y. Kim, S. Nahm, Y.-S. Kim, T.-H. Sung, and H.-C. Song, J. Am. Ceram. Soc. 96, 1024 (2013).

9. Y. B. Jeon, R. Sood, J. H. Jeong, and S. G. Kim, Sensors Actuators, A Phys. 122, 16 (2005).

10. G. Poulin, E. Sarraute, and F. Costa, Sensors Actuators, A Phys. 116, 461 (2004).

11. E. Ringgaard and T. Wurlitzer, J. Eur. Ceram. Soc. 25, 2701 (2005).

12. L. Ramajo, F. Rubio-Marcos, A. Del Campo, J. F. Fernández, M. S. Castro, and R. Parra, J. Mater. Sci. Mater. Electron. 26, 9402 (2015).

13. A. Prado-espinosa, M. Castro, and L. Ramajo, Ceram. Int. 43, 5505 (2017).

14. K. Wang and J. F. Li, J. Adv. Ceram. 1, 24 (2012).

15. B. Parija, T. Badapanda, S. K. K. Rout, L. S. S. Cavalcante, S. Panigrahi, E. Longo, N. C. C. Batista, and T. P. P. Sinha, Ceram. Int. 39, 4877 (2013).

16. A. Ullah, R. A. Malik, A. Ullah, D. S. Lee, S. J. Jeong, J. S. Lee, I. W. Kim, and C. W. Ahn, J. Eur. Ceram. Soc. 34, 29 (2014).

17. B. Wang, L. Luo, F. Ni, P. Du, W. Li, and H. Chen, J. Alloys Compd. 526, 79 (2012).

18. J. Camargo, A. Prado Espinosa, L. Ramajo, and M. Castro, J. Mater. Sci. Mater. Electron. 29, 5427 (2018).

19. M. Febbo and S. P. MacHado, J. Sound Vib. 332, 1465 (2013).

20. Sebastián P. Machado, Mariano Febbo, and S. Bellizzi, Mecánica Comput. Vol XXXIII 2185 (2014).

21. H. Ishii, H. Nagata, and T. Takenaka, Japanese J. Appl. Physics, Part 1 Regul. Pap. Short Notes Rev. Pap. 40, 5660 (2001).

22. J. E. Garcia and F. Rubio-Marcos, J. Appl. Phys. 127, 131102 (2020).

23. G. O. Jones, J. Kreisel, and P. A. Thomas, Powder Diffr. 17, 301 (2002). 
24. J. Camargo, L. Ramajo, F. Rubio-Marcos, and M. Castro, Adv. Mater. Res. 975, 3 (2014).

25. L. Ramajo, J. Camargo, F. Rubio-Marcos, and M. Castro, Ceram. Int. 41, 5380 (2015).

26. J. Kreisel, A. M. Glazer, G. Jones, P. A. Thomas, L. Abello, and G. Lucazeau, J. Phys. Condens. Matter 12, 3267 (2000).

27. A. Ullah, C. W. Ahn, A. Hussain, and I. W. Kim, Curr. Appl. Phys. 10, 1367 (2010).

28. A. Moosavi, M. A. Bahrevar, A. R. Aghaei, P. Ramos, M. Algueró, and H. Amorín, J. Phys. D. Appl. Phys. 47, 055304 (2014).

29. H. Nagata, M. Yoshida, Y. Makiuchi, and T. Takenaka, Japanese J. Appl. Physics, Part 1 Regul. Pap. Short Notes Rev. Pap. 42, 7401 (2003).

30. L. Dhakar, H. Liu, F. E. H. Tay, and C. Lee, Sensors Actuators, A Phys. 199, 344 (2013).

31. J. Wu, H. Shi, T. Zhao, Y. Yu, and S. Dong, Adv. Funct. Mater. 26, 7186 (2016).

32. Y. Oh, J. Noh, J. Yoo, J. Kang, L. Hwang, and J. Hong, IEEE Trans. Ultrason. Ferroelectr. Freq. Control 58, 1860 (2011).

33. X. Yan, M. Zheng, S. Sun, M. Zhu, and Y. Hou, Dalt. Trans. 47, 9257 (2018).

34. Z. Yang, S. Zhou, J. Zu, and D. Inman, Joule 2, 642 (2018). 